\title{
REVISIONISMO ILUSTRADO EM A BELA E A ADORMECIDA, DE NEIL GAIMAN E CHRIS RIDDELL
}

\author{
João Pedro Fernandes Gomes \\ Mestrando em Letras (Teoria da Literatura) pela Universidade Estadual Paulista Júlio de \\ Mesquita Filho (UNESP) / Campus de São José do Rio Preto \\ fernandesgomes.jp@gmail.com
}

\section{RESUMO}

A Bela e a Adormecida, dos britânicos Neil Gaiman e Chris Riddell, é um livro ilustrado publicado em 2014 que se destaca ao reformular elementos de dois contos de fadas canônicos, "Branca de Neve" e "A Bela Adormecida", integrandoos em um só. Faz isso propondo uma perspectiva revisionista, ressignificando elementos cristalizados e proporcionando um novo e mais crítico ângulo de análise (MARTINS, 2006). Este artigo usa os preceitos de Perry Nodelman (1988) para mostrar como o efeito revisionista pretendido pela obra se relaciona com as escolhas do ilustrador em relação ao texto-fonte. Percebemos que as imagens brincam com a expectativa do leitor ao destacarem elementos não usuais aos contos de fadas e subverterem convenções de livros ilustrados. As ilustrações agem, portanto, como potencializadoras do efeito revisionista presente no texto verbal, exercendo papel significativo para que a obra alcançasse tamanha notoriedade social e midiática

Palavras-chave: contos de fadas, ilustração, Branca de Neve, Bela Adormecida.

\section{ABSTRACT}

The Sleeper and the Spindle, by author Neil Gaiman and illustrator Chris Riddell, both British, was published in 2014. The book stands out by weaving narrative elements of two well-known fairy tales, Snow White and The Sleeping Beauty into one single story. It does so by introducing them through a revisionist perspective, thus ressignifying established elements from a new, more critical angle (MARTINS, 2006). This paper employs the work of Perry Nodelman (1988) to discuss how the book's revisionist effect is related to the choices of the illustrator regarding the written text. The artwork seems to play with readers' expectations by highlighting elements that are unusual to fairy tales as well as by subverting picture book conventions. Therefore, the illustrations maximize the revisionist effect of Gaiman's text, which played a significant role in the publicity garnered by the book upon its reception by the reading public and the media alike.

Keywords: fairy tales, illustration, Snow White, Sleeping Beauty. 


\section{Introdução}

No diálogo final de $A$ Bela e a Adormecida, um dos anões pergunta para Branca de Neve: "Você sabe que estamos indo para o leste, certo?". "Sei sim", ela responde (GAIMAN, 2015, p. 66, grifo do autor). A cena diz respeito ao fato de, após viver aventuras e enfrentar inúmeros perigos para salvar o reino, a rainha não mais desejar voltar para o castelo e se casar com o príncipe. Ela mostra a importância de abandonar expectativas impostas por outrem e tomar decisões fiéis à própria identidade, ressaltando o poder das escolhas. Levando em conta o trabalho aqui proposto, tais comentários ganham uma nova dimensão interpretativa ao se relacionarem também ao poder das ilustrações. Ao selecionar deliberadamente quais elementos do texto escrito seriam traduzidos para imagens, o ilustrador amplia o aspecto revisionista do conto de fadas (re)criado por Neil Gaiman.

A obra em questão é $A$ Bela e a Adormecida (no inglês, The Sleeper and the Spindle), produzida em conjunto pelo famoso escritor britânico e o premiado ilustrador Chris Riddell, e que teve sua primeira versão como livro ilustrado publicada em 2014. O projeto já era conhecido pelo público no formato de conto desde 2013 , quando fez parte da coletânea Rags \& Bones: New Twists on Timeless Tales. A narrativa reformula elementos de dois contos de fadas canônicos, "Branca de Neve" e "A Bela Adormecida", integrando-os em um só. Uma jovem rainha, incerta quanto à sua felicidade no reino que herdou, parte em uma jornada heroica quando uma maldição que faz todos adormecerem ameaça atingir seu povo, podendo ser quebrada apenas pelo despertar de uma princesa no alto de uma torre. Ao experienciar os obstáculos do percurso e 
confrontar a vilã, a rainha revive seus traumas passados e ganha a coragem necessária para tomar as rédeas de seu próprio futuro.

A reinterpretação de histórias do imaginário coletivo não é estranha à obra de Gaiman. O autor já havia utilizado elementos de várias mitologias na história em quadrinhos Sandman (1988-) e romances tais quais Deuses Americanos (2001), Os Filhos de Anansi (2005) e Belas Maldições (2006). Mesmo os contos de fadas, como mostra Snow, Glass, Apples (1994), já receberam atenção do autor, que também não é novato na coautoria de livros ilustrados. Contudo, A Bela e a Adormecida se destaca em sua vasta produção como um dos livros que mais chamou a atenção da mídia, principalmente pela cena de um beijo entre duas princesas de contos comumente associados ao público infantil.

Uma investigação prévia mostrou que, na verdade, o conteúdo considerado polêmico era mais predominantemente fruto da escolha do ilustrador, Chris Riddell, em destacar um momento fugaz do texto de Gaiman. Servindo o ocorrido como incentivo para esmiuçar a obra por completo, foi possível constatar que, de fato, grande parte do teor revisionista do texto é potencializado pela arte de Riddell, que rompe com as expectativas que o leitor possui, a partir de convenções, de livros ilustrados tradicionais. Por meio dos postulados teóricos de Perry Nodelman (1988), esta análise se dedica a explorar com maiores detalhes como essas relações arbitrárias do ilustrador perante o texto influenciam o produto final da obra.

Antes, contudo, exploremos o conceito de conto de fadas e revisionismo, para que se torne mais claro o impacto de tais decisões.

\section{Conto de fadas, revisionismo e livro ilustrado}


Apesar de ser fácil buscar na memória exemplos de contos de fadas conhecidos, conceituá-los é uma tarefa à qual vários estudiosos já se dedicaram, muitos deles se envolvendo em discussões que perduram até hoje. Para a contista Marina Colasanti (2015), o conto de fadas tem apelo universal e pode ser lido de infinitas maneiras pelos mais variados leitores, não só o público infanto-juvenil. Segundo a escritora, o que importa nos contos é seu conteúdo profundo, que trata de temas ligados à essência do ser humano. Nelly Novaes Coelho concordaria com o último ponto de Colasanti, pois considera que essas narrativas expressam atitudes humanas ligadas à realização do eu:

Com ou sem a presença de fadas (mas sempre com o maravilhoso), seus argumentos desenvolvem-se dentro da magia feérica (reis, rainhas, príncipes, princesas, fadas, gênios, bruxas, gigantes, anões, objetos mágicos, metamorfoses, tempo e espaço fora da realidade conhecida etc.) e têm como eixo gerador uma problemática existencial. [...] A efabulação básica do conto de fadas expressa os obstáculos ou provas que precisam ser vencidas, como um verdadeiro ritual iniciático, para que o herói alcance sua autorrealização existencial, seja pelo encontro de seu verdadeiro eu, seja pelo encontro da princesa [...] (COELHO, 1987, p. 12-14, grifos da autora).

Apesar de muito poder ser expandido sobre um conceito aparentemente simples, basta-nos agora dizer que é possível considerar A Bela e a Adormecida um conto de fadas, já que, dentre outras características fundamentais, é a busca existencial de Branca de Neve, como veremos mais a seguir, que move a narrativa. O que mais nos interessa saber é o que entender por revisionismo desses contos, já que é o fio condutor dos autores e de nossa análise.

Maria Cristina Martins sugere, com base na retomada de diversas críticas feministas antes dela, uma definição concisa de revisionismo de contos de fadas: 
Muitos textos revisionistas transgridem ou subvertem as narrativas tradicionais, contestando significados cristalizados nas histórias, de modo que, apesar do reconhecimento das fontes ser não somente possível como também desejável, é propiciado um distanciamento crítico em relação aos textos originais, expondo, por exemplo, o caráter sexista e misógino de muitas dessas histórias [...] numa atitude explícita de questionamento e desnudamento que evidencia uma recusa de conivência com a legitimação ou com a continuidade da tradição patriarcal (MARTINS, 2006, p. 158-159).

A atitude revisionista propõe, assim, que velhas histórias sejam contadas por novas perspectivas, geralmente visando suprir uma lacuna presente em suas versões originais. No caso de A Bela e a Adormecida, essa proposta tem como alvo duas princesas de contos de fadas famosos, vítimas de violências brutais e salvas por príncipes encantados, que menos agem e mais reagem em suas histórias.

O texto de Gaiman propõe um novo ângulo ao continuar a história de Branca de Neve após ser acordada de seu caixão de cristal. Tendo herdado o comando do reino e agora prestes a se casar com o príncipe que a salvou, ela se encontra na agonia de cumprir seu dever com o povo e formar uma família, apesar de saber que essa escolha não lhe trará felicidade. Revela-se no decorrer da narrativa que a falta de independência é resultado de um passado marcado pelas atitudes abusivas da madrasta, um fantasma que até hoje influencia suas ações.

Já Bela Adormecida entra em cena por meio da maldição sofrida após espetar o dedo no fuso de fiar. O sono, que no conto de origem faz adormecer todo o reino junto com a princesa, nesta versão se estende aos poucos até as terras de Branca de Neve. Vendo seu reino em perigo, a rainha toma para si o papel de heroína e parte para dar fim à maldição. Como seria revelado mais tarde, a donzela que dorme eternamente não é a princesa que espetou o dedo, mas a feiticeira maligna. Além de tornar Bela Adormecida a 
sua escrava guardiã, ela se alimenta da energia vital de todos os que adormecem, mantendo assim sua juventude.

O que começa como um conto de fadas comum vai, assim, ganhando camadas de desenvolvimento das quais nenhuma das personagens usufruía antes, tendência que se constitui a partir do texto e ganha novas dimensões na ilustração. Esse movimento, no entanto, começa muito antes que as primeiras palavras do conto sejam lidas.

\section{O livro enquanto objeto: aspectos gráficos significativos}

Não só da relação entre autor e ilustrador é feito o livro ilustrado. Outra entidade fundamental nas escolhas criativas e gráficas acerca do livro deve ser levada em conta: a editora. No caso de $A$ Bela e a Adormecida, a Bloomsbury, que inspirou a edição brasileira da Rocco Jovens Leitores, também contribuiu amplamente em escolhas editoriais que reforçam o potencial revisionista.

Esse efeito se deu pelo fato de que, apesar de conter em suas páginas uma narrativa que subverte conceitos canônicos dos contos, o livro em si toma uma direção contrária, retomando convenções antigas utilizadas em alguns dos primeiros livros ilustrados do fim da Idade Média:

No século XIV, Jean Pucelle, o excepcional pintor de miniaturas, desenvolveu um estilo refinado que influenciou as iluminuras por dois séculos. [...] Texto e decoração se tornaram um só, e incluíam pequenas miniaturas emolduradas, bem como figuras dispostas livremente na borda inferior. Pucelle não mais usava fundos sólidos de ouro, mas uma moldura ornamental em torno do texto composta de fontes, folhas, insetos, flores e pássaros cobertos de ouro (CHRISTENSEN, 1959, p. 200, tradução nossa). ${ }^{i}$ 
O trecho, que retoma uma etapa da história da arte ocidental, permite que percebamos características em comum com a obra aqui analisada e os livros ilustrados séculos atrás. A mais marcante, talvez, seja a ornamentação das bordas com temas florais e o uso do ouro, observável logo nas ilustrações iniciais de A Bela e a Adormecida.

Figura 1 - Ilustração que acompanha a folha de rosto

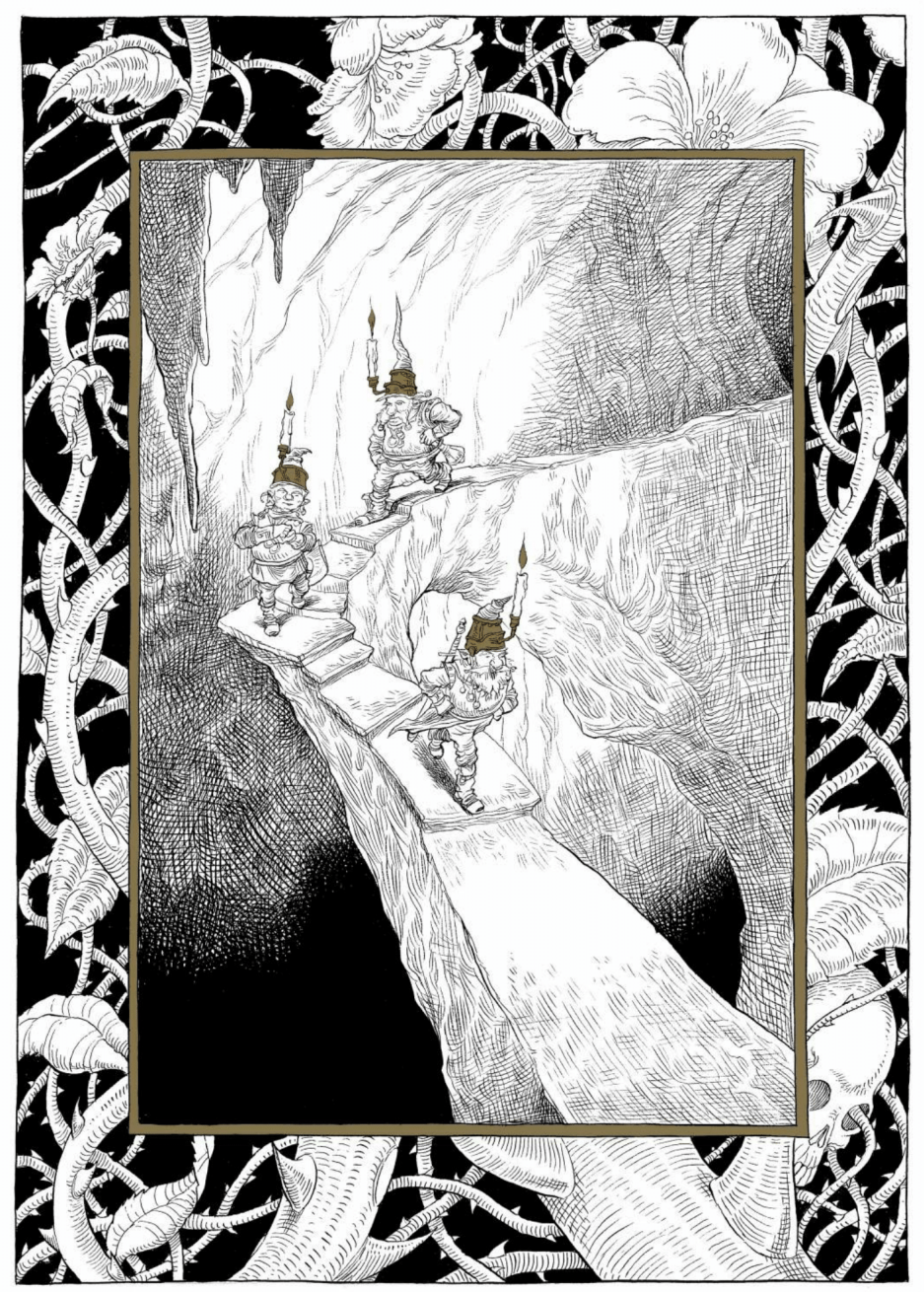

Fonte: GAIMAN, 2015, p. 6.

A ornamentação é característica fundamental da obra mais importante da Idade Média: a Bíblia. Foi nas versões produzidas pelos monges escribas que se observaram as mais imponentes letras capitulares, bordas floridas e uso do ouro (VISALLI; GODOI, 2016). 
Dessa forma, tais elementos acabaram sempre sendo associados com esse período histórico e com a literatura sacra, e seu uso em livros contemporâneos quase inevitavelmente revive tal atmosfera. A Bela e a Adormecida é um desses casos, utilizando a seu favor a onipotência desses textos: subliminarmente faz o leitor esperar um conteúdo tradicional, familiar e moralmente aceitável, levando à inevitável surpresa. Simultaneamente, isso dá ao conteúdo revisionista um tratamento gráfico similar ao de histórias consagradas, elevando-o de seu status que poderia ser considerado marginal em relação aos contos-fonte.

Ainda nesse jogo gráfico de tensões entre tradição e inovação, o papel vegetal da sobrecapa torna embaçada e distante a figura da moça adormecida sob ele, e cria a sensação de mistério e distanciamento entre leitor e personagem. É preciso que ele atravesse esse véu semiopaco caso deseje conhecer o que se esconde além dele. Como uma vidraça que dificulta a visão e passagem do leitor, a sobrecapa é complementada por mais obstáculos na forma dos espinhos dourados que a ilustram, desconvidando ao toque. O segredo que protegem, por sua vez, é a já esperada princesa adormecida, que repousa inerte, mas cuja identidade virá a ser uma surpresa dentro da história.

A sobrecapa tem, assim, duplo significado. A princípio, retrata a dificuldade em atingir a donzela e romper a maldição, jornada que imita a do príncipe do conto da Bela Adormecida. Ao mesmo tempo desestimula o leitor a chegar até ela, como se indicasse pelos espinhos abundantes e pelas rosas pretas da capa que a bela moça não é o que parece ser. Dessa forma, a edição gráfica promove o conto como algo de caráter antigo, já esperado, longe da realidade contemporânea e questionadora de valores na qual se situa o leitor. Depois que o conteúdo do livro é conhecido, entretanto, ela pode ser lida de forma menos óbvia, refletindo os valores revisionistas e alertando que o belo nem 
sempre é bom, ou que é impossível entrar nos contos sem se ferir com os espinhos metafóricos subjacentes a eles.

Notamos que variadas escolhas editoriais se esforçam para tentar situar a narrativa num imaginário familiar ao leitor de contos de fadas, que, como pretendido, julga conhecer a história a ser apresentada. Além disso, ao ornamentar as imagens com nobres pigmentos dourados e bordas ilustradas, a edição do livro parece retomar o aspecto sacro e intocável que a ilustração possuía em seus primórdios, retomando valores ligados à canonicidade, elevação e tradição do conteúdo. Esse conjunto de elementos contribui na criação de uma atitude do leitor perante o que vai ser lido, que acredita estar longe de uma atualização revisionista. É justamente por isso que a narrativa tem mais chances arrebatá-lo.

\section{Era uma vez Branca de Neve infeliz}

Apesar de o efeito revisionista começar mesmo antes do início da leitura do conto de Neil Gaiman, é no texto que todas as outras construções se apoiam para elaborar sentidos, em particular as ilustrações. Com isso em mente, voltamos agora nossas atenções para as relações entre ambos, analisando alguns casos exemplares.

A começar por um dos primeiros momentos da narrativa, que nos apresenta visualmente pela primeira vez à rainha, protagonista da história. 
Figura 2 - "A rainha acordou cedo naquela manhã” iii

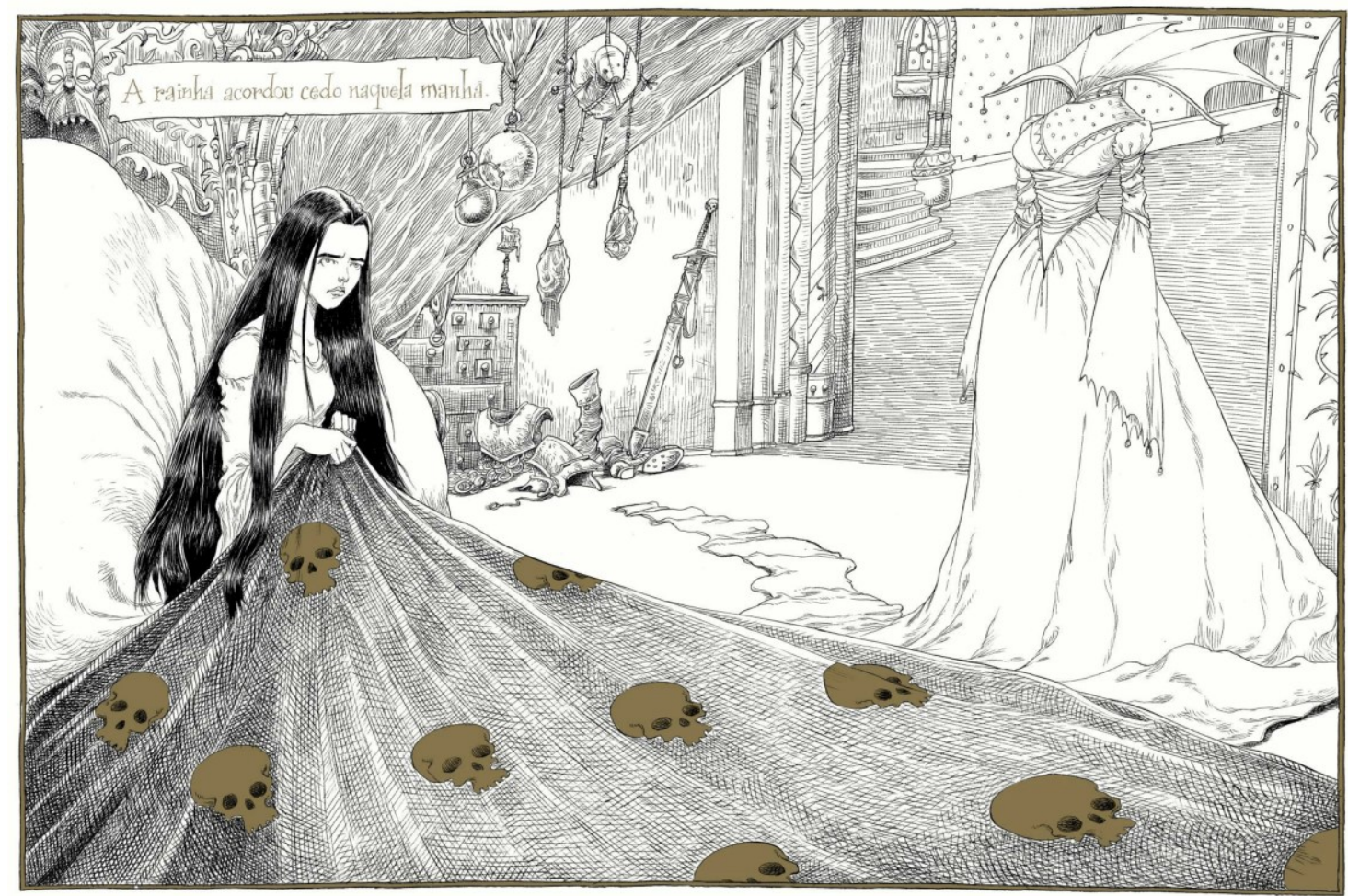

Fonte: GAIMAN, 2015, p. 12.

De início, o que mais atrai a atenção na figura é Branca de Neve. Ela é a única figura humana da cena, o que cognitivamente nos atrai pela similaridade conosco, e está à esquerda da imagem, parte que tendemos a ler primeiro por influência da leitura ocidental das palavras da esquerda para a direita (NODELMAN, 1988). Seu cabelo escuro também é o objeto mais denso da figura. No entanto, o mais interessante talvez sejam as caveiras de sua manta, que, destacadas em dourado, apontam diretamente para a rainha. São reveladores tanto o fato de elas serem o único elemento colorido da figura - já que, simbolicamente, o esqueleto é associado à morte e temas fúnebres - como o de a rainha literalmente se cobrir com esses crânios, parecendo puxar a manta para perto de si. A personagem se esconde, portanto, sob uma pesada camada de morte simbólica, o que pode ser interpretado à luz de revelações futuras da história, como os traumas passados que ainda a assombram. 
Segundo Nodelman (1988), o fato de a ilustração ocupar uma página dupla também implica em algumas convenções. Entre elas, a de que cada uma das páginas deve conter certa independência, já que a dobra do livro pode deformar objetos importantes caso estejam no centro da figura, desencorajando seu posicionamento nessa área. 0 autor diz, ainda, que elementos opostos simetricamente, em geral, possuem algum vínculo de similaridade ou contraste, como numa relação espelhada. Ambas as asserções não poderiam ser melhor exemplificadas na ilustração. Se, em uma página, temos a rainha infeliz, na outra, simetricamente oposto a ela se encontra o traje real, que pode ser lido como uma possível razão para sua melancolia.

A sensação geral de desconforto do vestido não é aleatória. As faixas na cintura e nos braços parecem comprimir o corpo do manequim (aliás, descobrimos logo em seguida que se trata de seu vestido de noiva, o que reforça o desconforto ali sugerido). Além disso, pode-se pontuar sua angulosidade, já que é composto por motivos triangulares e extremidades pontiagudas:

[...] A forma dos objetos ilustrados em relação ao seu plano de fundo e a outros objetos pode criar tensões específicas e, portanto, sugerir sentidos em si mesmos. Tendemos a supor que quadrados são rígidos e formas arredondadas, aconchegantes. [...] Da mesma forma que chamam atenção para si mesmas, as formas e texturas dos objetos podem nos fazer prestar atenção em outros objetos em uma figura. Por exemplo, um objeto que direciona para algum ponto tende a focar nossa atenção menos em si do que na coisa à qual aponta (NODELMAN, 1988, p. 126-128, tradução nossa). ${ }^{\text {iv }}$

O último trecho da citação pode ser associado, por sua vez, à cauda do traje, que se estende em formato de seta para a armadura no canto da parede, fazendo com que seja notada. Não só a armadura tem formas mais arredondadas que as do vestido, como 
também se encontra próxima à rainha, na página esquerda, juntamente da cabeceira torta da cama, da vela gasta e do móbile de bugigangas macabras penduradas no teto. Esse cenário contrasta diretamente com a luminosidade, elegância e limpeza da página direita. Contrapõe-se, então, sua identidade desajustada e sombria em relação ao reino luminoso e ordenado onde vive, metonimizado pelo castelo.

Até então, pode parecer que as informações sobre a rainha são obtidas muito mais pelos recursos da ilustração do que pelo texto verbal em si. Contudo, "as palavras mudam os sentidos das imagens, e então as imagens mudam os sentidos das palavras às vezes confirmando nossas expectativas e às vezes nos surpreendendo por não confirmá-las" (NODELMAN, 1988, p. 219, tradução nossa)v . Temos aqui o segundo caso: a legenda da imagem, "A rainha acordou cedo naquela manhã" (GAIMAN, 2015, p. 12), é irônica quando comparada à ideia graciosa que se tem de uma donzela despertando ao alvorecer. Logo, o leitor é levado a constatar, pelo contraste entre texto e imagem, que ela está prestes a enfrentar, a contragosto, mais um dia infeliz que em nada a motiva a sair da cama.

\section{Um beijo sem amor verdadeiro}

Se o primeiro encontro com uma figura da Branca de Neve é cheio de informações contextuais e simbólicas, basta avançar um pouco na narrativa para perceber que há ilustrações com forças significativas de outra ordem, como a que analisaremos agora.

Como sabemos, mesmo que uma ilustração possa expressar sentidos que o autor não tenha racionalmente intencionado, aquilo que acaba na página nunca é fruto de um processo imparcial, pois sempre tem origem nas escolhas do artista a partir do texto- 
fonte. A figura 3 foi o motivo de A Bela e a Adormecida ter recebido críticas na época de sua publicação pelo dito teor homossexual do livro.

Figura $3-0$ beijo da rainha desperta a donzela

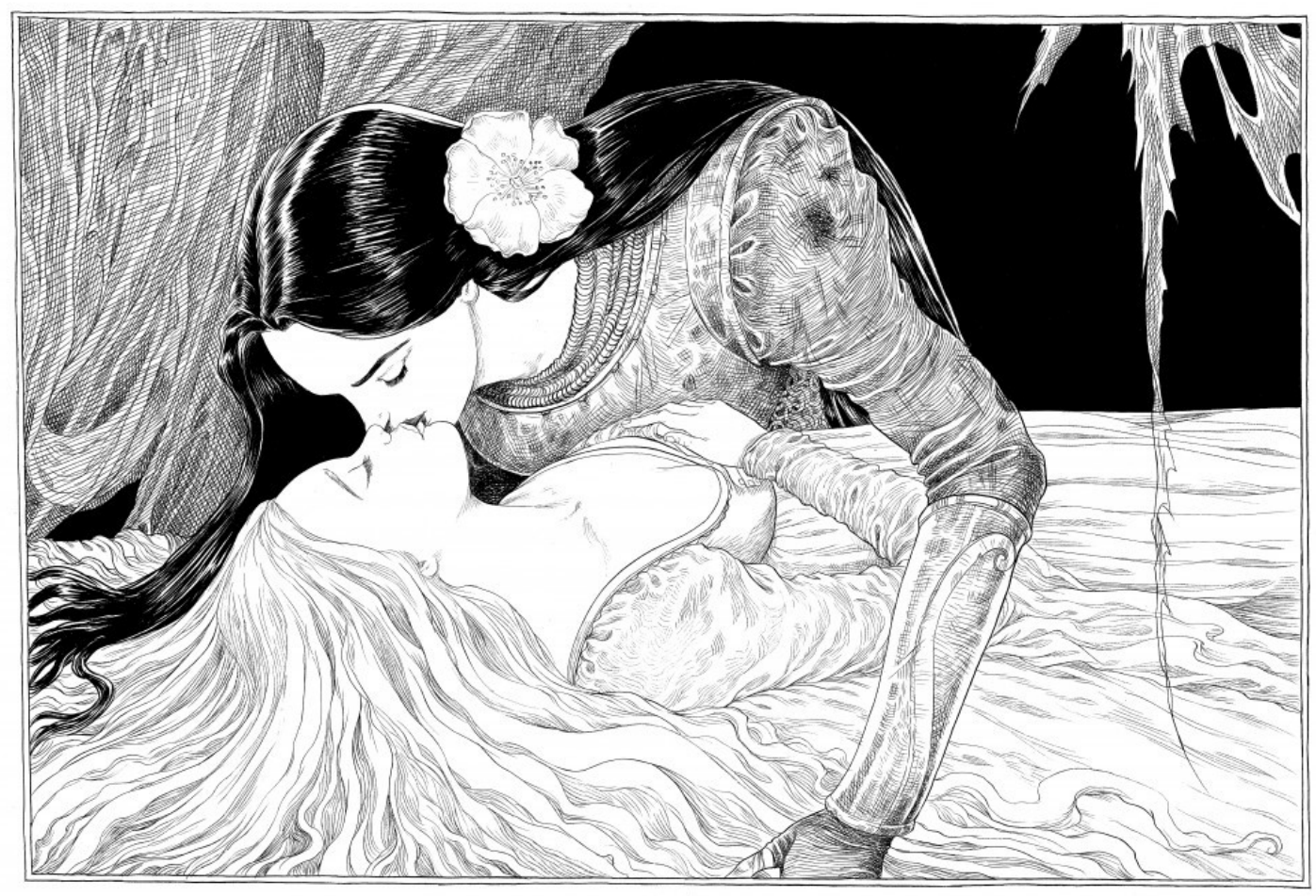

Fonte: GAIMAN, 2015, p. 50-51.

Agora, vejamos o trecho do conto que se relaciona com o momento retratado:

[A rainha] andou até a cama e puxou o cortinado. O rosto da adormecida os encarava cegamente.

[...]

- Bem - disse o terceiro [anão]. - Alguém precisa fazer as honras.

- Eu faço - disse a rainha, baixinho.

Ela aproximou o rosto da mulher adormecida. Seus lábios cor de carmim tocaram a boca cor-de-rosa da outra num beijo prolongado e intenso (GAIMAN, 2015, p. 49). 
Aqui se intercalam as duas páginas ocupadas pela ilustração, seguidas pela continuação do diálogo:

\author{
- Funcionou? - perguntou um dos anões. \\ - Não sei - respondeu a rainha. - Mas tenho pena dela, \\ coitadinha. Passar a vida toda dormindo. \\ - Você dormiu um ano inteiro nesse mesmo sono das bruxas - \\ apontou o anão. - E não morreu de fome. Seu corpo não apodreceu \\ (GAIMAN, 2015, p. 52).
}

Mais uma vez, ocorre a escolha de uma ilustração que ocupa todo o espaço de uma página dupla, apesar de nesta ocasião haver menos elementos aparentes para serem analisados: o foco está todo direcionado à ação. O beijo entre a suposta princesa e a rainha é posto quase como um clímax visual, apesar de ser uma ação que, no texto escrito, após meros instantes não recebe atenção alguma. Talvez por isso a polêmica tenha se instaurado: sem o texto ao lado, imaginar-se-ia que a cena é muito mais relevante ao conto, visto que o beijo sempre compõe o ápice do conto de fadas e leva ao final feliz.

Recebendo tanto destaque na ilustração, fica evidente que, de novo, as escolhas em torno do livro foram tomadas pensando em seu aspecto revisionista, dessa vez salientando a interação homossexual. Um argumento é justamente o de retratarem o ato do beijo em si, e não segundos antes da ação climática acontecer, como é o padrão nos livros ilustrados:

[...] Ao imaginar a inevitável sequência ao que de fato vemos, nós mesmos criamos o movimento. Livros ilustrados estão repletos de imagens que mostram uma ação logo antes de ela atingir seu clímax [...]; nesse meio de contar de histórias, evocar a ação é essencial (NODELMAN, 1988, p. 160, grifo do autor, tradução nossa). ${ }^{\text {vi }}$ 
Ilustrar o ato em plena execução não deixa dúvidas de que ele aconteceu; mais do que isso, a figura congela a imagem e opta pela sensação de prolongamento da duração da ação em vez da sugestão de movimento. Isso explica outro ponto significativo: o posicionamento da ilustração entre trechos estratégicos do texto, logo após o toque "prolongado e intenso" dos lábios e antes da conversa casual que diluiria rapidamente o peso da cena. A ilustração, nesse caso, influencia na criação de sentido do texto, prolongando a duração da parte considerada subversiva.

Esse está longe de ser o único atrativo da imagem. Não deixa de ser interessante o contraste entre as duas moças, nas diversas polarizações das vestes masculinizadas de Branca de Neve - Nodelman (1988) aponta que personagens femininas com traços masculinos são indicativos de agressividade ou vilania - contra os delicados tecidos da donzela adormecida, a real vilã. Ou, ainda, a simbologia da flor no cabelo, contrastando com a personalidade e atitudes aventureiras mostradas pela rainha até então. $\mathrm{O}$ uso de tons claros e escuros, contudo, é o que mais nos interessa agora, pois mais uma vez são invertidos, colocando o escuro como característica da mocinha e o claro na esfera do malfeitor. Uma outra ilustração, no entanto, é mais propícia para explorar essa batalha de inversos.

\section{Quando o belo é mau e o feio é bom}

Pouco antes de Branca de Neve e os três anões chegarem ao castelo, descobrimos que a jovem adormecida não é a única na torre. Há uma velha senhora, única pessoa acordada em todo o reino, que perambula pelas redondezas. Temos a seguinte cena: 
Figura $4-0$ embate silencioso entre a velha e a jovem

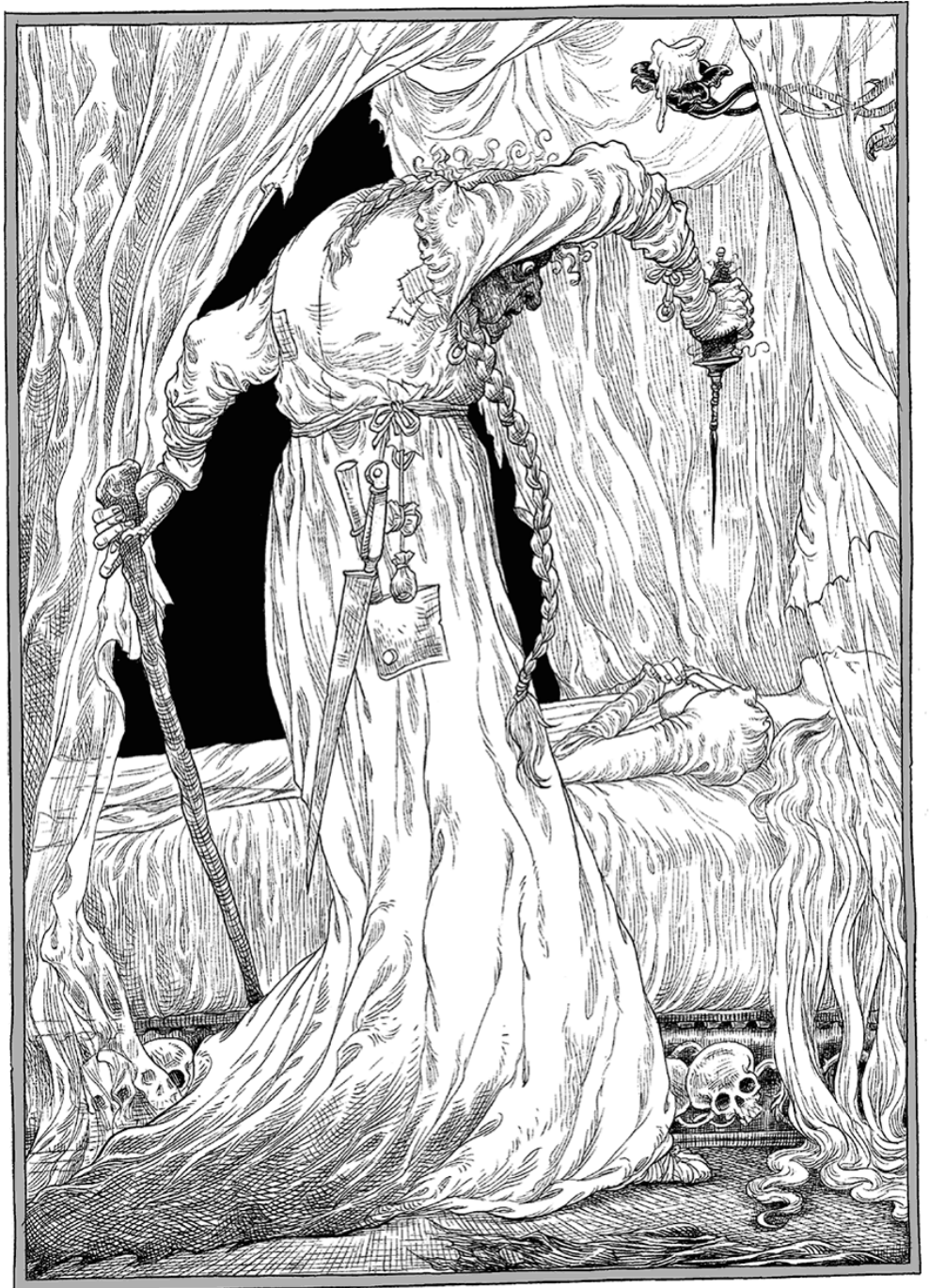

Fonte: GAIMAN, 2015, p. 39.

Tudo na imagem sugere que a velha senhora é a vilã, ideia amparada pelo texto:

A velha curvou o corpo e pegou o fuso. E disse bem alto:

- Se eu cravasse esse fuso no seu coração, você não continuaria assim tão lindinha, não é? Hein? Continuaria?

Ela foi até a menina de vestido branco e empoeirado que dormia. Mas abaixou o braço.

- Não. Eu não consigo. Por todos os deuses, como eu gostaria de conseguir (GAIMAN, 2015, p. 38). 
Apesar de o texto indicar que o ato violento não se completa, a ilustração não dá indícios disso. Faz, pelo contrário, o que a ilustração do beijo não fez, escolhendo retratar o momento logo antes do ápice da ação, levando o leitor a completar mentalmente um gesto dramático que, ora, não acontece. A tensão, apesar disso, está ali, desde as facas penduradas no cinto da mulher, em nenhum momento mencionadas no texto, passando pelos tecidos fantasmagóricos do dossel, até as caveiras sob a cama, como um prelúdio de que a morte está para macular o local. Mas, como indício maior, temos o rosto sombrio e urgente da velha:

Algumas das mais óbvias informações narrativas sugeridas pelos objetos das ilustrações se relacionam com nossos pressupostos culturais mais básicos. O escuro tende a representar o mal, e a luz, o bem; muitos livros ilustrados mostram personagens maus nas sombras e personagens bons à luz do sol - ou os protagonistas tristes no escuro e os felizes na luz (NODELMAN, 1988, p. 111, tradução nossa). vii

Do modo como é retratada, a personagem não sugere tristeza. Na verdade, como segunda característica mais evidente está a velhice: "o cabelo da mulher era cinza raiado de branco e tão ralo que o couro cabeludo ficava à mostra. Ela coxeava enraivecida pelo palácio, apoiada em sua bengala, como se movida por ódio e nada mais, batendo portas e falando sozinha enquanto andava" (GAIMAN, 2015, p. 33). Como seria possível uma figura tão feia não ser má? Afinal,

[...] Raramente existem heróis feios ou vilões bonitos em versões ilustradas de contos de fadas - pressupondo, é claro, nossos valores sociais de praxe sobre o que constitui beleza e feiura. [...] Não obstante, livros ilustrados ainda dependem, em uma escala surpreendente, dos clichês de aparência física (NODELMAN, 1988, p. 113, tradução nossa). viii 
É justamente essa rara inversão de clichês que acontece aqui. Após acordada, a donzela adormecida se revela a vilã da história, uma feiticeira que, no passado, amaldiçoou a princesa ao espetar seu dedo na roca encantada. Pelo feitiço, toda a população do reino dormiria enquanto a bruxa absorveria sua juventude. Enquanto isso, a jovem que jamais teve a chance de ser a Bela Adormecida que conhecemos ficaria como guardiã da bruxa, sendo incapaz de fazer a ela qualquer mal.

Ao final, apesar de todas as quebras de expectativas ao longo de todo o livro, o encerramento é por um final relativamente feliz. A bruxa é derrotada e todo o reino é acordado, apesar de a verdadeira princesa não obter sua juventude de volta. É colocada, contudo, na cama em que antes repousava a feiticeira, para que enfim possa ter seu longo e justo sono. Onde haviam crânios, do tecido da colcha à cabeceira da cama, agora são vistas grandes flores brancas. O único esqueleto presente após a derrota da malfeitora aparece abandonado ao canto da parede: são os restos mortais da bruxa recém-derrotada. Ficam esquecidos, como era também esquecida a armadura de Branca de Neve antes de ela a vestir uma última e definitiva vez para viver a aventura que definiria seu destino.

\section{Considerações finais}

Este trabalho teve como objetivo investigar como as ilustrações de Chris Riddell para A Bela e a Adormecida contribuíram para a amplificação do exercício de revisionismo presente no conto de Neil Gaiman. Foram escolhidas ilustrações emblemáticas que fornecessem o insumo necessário para discussões produtivas sobre a obra e, na medida do possível, preenchidas as lacunas sobre a história para facilitar a leitura àqueles que 
desconhecem o livro. Assim, espera-se ter sido mostrado, a partir da análise, que aquilo que se espera de um conto de fadas ilustrado pode não seguir os moldes convencionais desse gênero, mas mesmo assim (ou, talvez, exatamente por isso) ser uma obra rica em possibilidades interpretativas.

Muito mais pode ainda ser dito sobre este livro nos estudos da ilustração e dos contos de fadas, abordando as inúmeras relações de paralelismo nas páginas duplamente ilustradas, investigando mais a fundo os símbolos abundantes em toda a narrativa ou mesmo averiguando por quais outros mecanismos opera o ato revisionista da obra. Foi lançado apenas mais um dos incontáveis olhares que os livros ilustrados aguardam ansiosamente receber. Sejam ou não contos de fadas, essas publicações sempre conectam texto e imagem de forma a estabelecer relações mágicas. Basta ceder à curiosidade que nos instiga e partir na grande aventura que é desvendá-las.

\section{Referências}

CHRISTENSEN, E. O. The history of Western Art. New York/Toronto: The New American Library, 1959.

COELHO, N. N. O conto de fadas. São Paulo: Ática, 1987.

GAIMAN, N. A Bela e a Adormecida. Ilustrações de Chris Riddell. Tradução Renata Pettengill. Rio de Janeiro: Rocco Jovens Leitores, 2015.

MARINA Colasanti explica o que são histórias maravilhosas ou contos de fada. Produção do Grupo Editorial Global. 2015, 2 min, son., color. Disponível em: <https://www.youtube.com/watch?v=gTcEjthGfoE>. Acesso em: 16 jul. 2018.

MARTINS, M. C. Histórias que nossas Mães não nos Contaram: o revisionismo feminista dos contos de fadas. Em Tese, v. 10, p. 157-163, dez. 2006. 
NODELMAN, P. Words About Pictures: The Narrative Art of Children's Picture Books. Athens: University of Georgia Press, 1988.

VISALLI, A. M.; GODOI, P. W. Estudos sobre imagens medievais: o caso das iluminuras. Diálogos, v. 20, n. 3, p. 129-144, 2016.

\section{Recebido em 21 de fevereiro de 2019.}

Aceite em 19 de março de 2019.

\footnotetext{
$i$ "In the fourteenth century, Jean Pucelle, the outstanding miniature painter, developed a refined style that influenced illumination for two centuries [...]. Text and decoration became a unit, and included small miniatures in frames as well as freely disposed figures on the lower border. Pucelle no longer used solid gold backgrounds, but an ornamental frame around the text of springs, leaves, insects, flowers, and birds in gilt color."

ii As partes em marrom têm aplicações em dourado.

iii Os detalhes em marrom são dourados na versão impressa.

iv "[...] the shape of visual objects as they relate to their background and to other objects can create specific tensions and thus imply meaning in themselves. We tend to assume that squares are rigid and that rounded shapes are accommodating; [...] As well as drawing attention to themselves, the shapes and textures of objects can make us pay attention to other objects in a picture. For instance, and object that comes to a point tends to focus our attention less on itself than on what it points toward."
}

$\checkmark$ "[...] the words change the meanings of the pictures, and the pictures then change the meaning of the words - sometimes by confirming our expectations and sometimes surprising us by not confirming them"

vi "[...] in imagining the inevitable follow-through of what we actually see, we ourselves create the motion. Picture books are filled with pictures that show an action just before it reaches its climax [...]; in this storytelling medium, the evocation of action is of the essence."

vii "Some of the more obvious narrative information implied by the objects in pictures relates to our most basic cultural assumptions. Dark tends to represent evil, light goodness; many picture books show evil characters in the shadows and good ones in the sunlight - or sad protagonists in the dark and happy ones in the light."

viii “[...] there are rarely ugly heroes or handsome villains in illustrated versions of fairy tales - assuming, of course, our usual societal values about what constitutes beauty and ugliness. [...] Nevertheless, picture books still depend to an astonishing extent on clichés of physical appearance." 